\title{
Configurações
}

Revista de sociologia

$25 \mid 2020$

Debater o desenvolvimento: questões, dilemas e alternativas

\section{Desenvolvimento e desigualdades: Barcelos em contexto regional}

Development and inequalities: Barcelos in a regional context

Développement et inégalités: Barcelos dans un contexte régional

\section{António Cardoso}

\section{OpenEdition}

\section{Journals}

\section{Edição electrónica}

URL: http://journals.openedition.org/configuracoes/8953

DOI: 10.4000/configuracoes.8953

ISSN: 2182-7419

\section{Editora}

Centro de Investigação em Ciências Sociais

\section{Edição impressa}

Paginação: 128-153

ISSN: 1646-5075

\section{Refêrencia eletrónica}

António Cardoso, «Desenvolvimento e desigualdades: Barcelos em contexto regional », Configurações [Online], 25 | 2020, posto online no dia 23 junho 2020, consultado o 25 junho 2020. URL : http:// journals.openedition.org/configuracoes/8953; DOI : https://doi.org/10.4000/configuracoes.8953 
Cardoso, António - Desenvolvimento e desigualdades: Barcelos em contexto regional. Configurações, vol. 25, 2020, pp. 128-153.

\title{
Desenvolvimento e desigualdades: Barcelos em contexto regional
}

\author{
ANTÓNIO CARDOSO *
}

Instituto Politécnico de Viana do Castelo, Centro Interdisciplinar de Ciências Sociais-Universidade do Minho

\begin{abstract}
Resumo
Após oferecer um retrato sintético do desenvolvimento desigual em termos regionais e, em especial, do concelho de Barcelos, com dados comparativos e atualizados, parte-se da seguinte questão: em relação aos indicadores médios do país e regionais, qual é a posição do concelho de Barcelos no quadro regional e nacional? Os dados estatísticos do INE e de outras fontes e estudos evidenciam a existência de desigualdades sociais, socioeducativas e culturais. Dos resultados de estudo conclui-se que estamos perante uma região semiperiférica e uma economia de crescimento desigual e vulnerável.
\end{abstract}

Palavras-chave: Território, desenvolvimento, desigualdades, Minho/Barcelos, Portugal.

\begin{abstract}
Development and inequalities: Barcelos in a regional context

After offering a synthetic portrait of the unequal development in regional terms and, in particular, of the municipality of Barcelos, with comparative and updated data, we start with the following question: compared to the country's and regional average indicators, what is the position of Barcelos in the regional and national context? The statistical data from the INE (Statistics Portugal) and other sources and studies, show the existence of social, socio-educational and cultural inequalities. From the study results, we conclude that this is a semi-peripheral region with unequal and vulnerable economic growth.
\end{abstract}

Keywords: Territory, development, inequalities, Minho/Barcelos, Portugal.

*E-mail: amfc2008@gmail.com 


\section{Résumé \\ Développement et inégalités: Barcelos dans un contexte régional}

Après avoir présenté un portrait sommaire du développement inégal en termes régionaux et, particulièrement, dans la municipalité de Barcelos, avec des données comparatives actualisées, nous partons de la question suivante : en ce qui concerne les indicateurs moyens du pays et de la région, quelle est la situation de Barcelos dans le cadre régional et national ? Les statistiques de l'INE et d'autres sources et études démontrent l'existence d'inégalités sociales, socio-éducatives et culturelles. Les résultats de l'étude nous permettent de conclure que nous sommes en face d'une région semi-périphérique et d'une économie à la croissance inégale et vulnérable.

Mots-clés: Territoire, développement, inégalités, Minho/Barcelos, Portugal.

\section{Introdução e problema}

O tema do desenvolvimento tem sido recorrente ao longo da história. Questões sobre o desenvolvimento relacionadas com as desigualdades (sociais, económicas, culturais, territoriais e ambientais) têm nos últimos anos merecido a atenção de diversas instituições e atores sociais; continuam a ser objeto de diferentes interpretações, desde as clássicas até as mais recentes (Silva, 2009; Bader \& Benschop, 2018; Silva, 2018). O problema tem suscitado o debate, particularmente desde a crise de 2008, nas diversas dimensões, no seio das autoridades governamentais de vários países - incluindo Portugal - e organizações internacionais (União Europeia, Banco Central Europeu, Fundo Monetário Internacional, Organização das Nações Unidas para a Alimentação e Agricultura - FAO, Banco Mundial), organizações políticas e partidos, assim como entre os académicos, a comunicação social e a sociedade civil em geral. As desigualdades são imensas, complexas e diferenciadas. O tema continua a ser controverso. Vários são os indicadores e os estudos'.

O fenómeno das desigualdades no quadro de um desenvolvimento desigual, sendo um fenómeno multidimensional e transversal às sociedades contemporâneas, afeta famílias, classes, etnias, género, crianças, idosos, territórios e cidades, lugares e bairros. Tais assimetrias colocam em desvantagem os mais diversos grupos sociais na acessibilidade e fruição de recursos tais como educação, saúde, trabalho, habitação, justiça, ambiente, rendimento e qualidade de vida, em geral.

A partir dos diversos indicadores expressos em termos económicos, sociais e culturais, pretende-se analisar e, subsequentemente, fazer uma síntese sobre o estado do (sub)desenvolvimento da região do Minho e, com particular enfoque, no município de Barcelos em contexto regional. Barcelos localiza-se na NUTS Cávado e apresenta, por razões de proximidade geográfica, múltiplas interdependências

1 Cf., entre outros, Carmo (2010); A. Costa (2012); Remoaldo e Nogueira (2012); Almeida (2013); Diogo \& Diogo (2013); Silva \& Cardoso (2003); Silva (2009); Rodrigues et al. (2012); Ribeiro (2018); Gomes et al. (2018) e Baltazar (2018). 
e similitudes, nomeadamente a nível sociodemográfico e económico, relativamente aos demais municípios do quadrilátero urbano² (Braga, V. N. Famalicão e Guimarães), ao mesmo tempo que se diferencia de outros, sobretudo dos municípios do Minho interior. Para se ter uma ideia de conjunto, recorreu-se a estatísticas do Instituto Nacional de Estatística e de outras fontes institucionais, de primeira e segunda mão, problematizando a relação entre espaço e sociedade e seu processo em termos de (sub)desenvolvimento. Por isso, proceder-se-á a uma breve análise sociodemográfica da região do $\mathrm{Minho}^{3}$, destacando especificamente o município de Barcelos na NUTS Cávado mas, no quadro das unidades territoriais do Cávado e do Ave, sem descuidar alguma comparação mais a norte com a NUTS Alto Minho e a sul com o Porto e, de modo mais amplo, com a região norte e o país.

A questão que, com pertinência, se pode colocar é, entre outras, a seguinte: em relação aos indicadores médios do país, qual é a posição do concelho de Barcelos em contexto regional e nacional? E, se o lugar é periférico em relação a regiões centrais, por que é que se mantêm e persistem desigualdades? Sendo questões algo complexas e que não cabe aqui dar uma cabal resposta, far-se-á um breve diagnóstico em termos comparativos, com base em dados estatísticos e alguns estudos consultados.

\section{Desenvolvimento: perspetivas}

Colocada a questão, importa rever as principais correntes e interpretações sobre o conceito de desenvolvimento. Neste sentido, impõe-se, seguindo Silva e Cardoso (2005), uma análise sobre o processo de desenvolvimento, considerando-se a complexidade do conceito e os contributos das principais teorias do desenvolvimento: a teoria (neo)liberal do crescimento e da modernização, defensora do crescimento económico e da mudança para a modernização (Rostow, 1960; Parsons, 1964); a teoria neo-institucional, crítica da perspetiva neoliberal, que assume a importância do papel do Estado no desenvolvimento e na correção das assimetrias regionais e sociais (Myrdal, 1974), promovendo a reforma com vista à resolução dos problemas do desenvolvimento; a visão marxista, defensora de um processo revolucionário

\footnotetext{
2 Em 2008 foi criado o quadrilátero urbano, formado pelas cidades de Braga, Barcelos, Guimarães e V. N. de Famalicão, tendo por base questões da competitividade e internacionalização.

3 De acordo com a Nomenclatura das Unidades Territoriais para Fins Estatísticos (NUTS), versão 2013, o Minho com 24 concelhos no seu território corresponde às NUTS III: Alto Minho, com 10 concelhos; Cávado com 6 concelhos; e Ave, com 8 concelhos, totalizando uma área de $4916 \mathrm{~km}^{2}$ (cerca de 5,33\% do território nacional), com um total de 798 freguesias (546 segundo a reestruturação administrativa de 2012/2013). É uma região de minifúndio, que se divide em três NUTS: a do Alto Minho, com 232178 indivíduos numa média de 104,6 hab/ $\mathrm{km}^{2}$; a do Cávado, com 403953 residentes, numa média de 324,3 hab/ $\mathrm{km}^{2}$ e a NUTS do Ave com 413854 indivíduos, numa média de $285,2 \mathrm{hab} / \mathrm{km}^{2}$. A população das NUTS Minho-Lima (atualmente denominada de Alto Minho), Ave e Cávado, que em 2001 somava 1153306 indivíduos, ascende em 2011 a um total de 1166742 residentes, e que em 31 de dezembro de 2017 se estimava em 1049951 habitantes (INE, Censos 2001, 2011 e Anuário Estatístico da Região Norte, 2017), o que significa que a região perdeu mais de 103 mil habitantes em cerca de 16 anos, ou seja, 6400 pessoas, aproximadamente, por ano.
} 
essencial ao progresso e, no seio desta visão crítica marxista, as teorias da dependência e do centro-periferia, partindo do pressuposto que os países centrais têm determinado a dependência das economias subdesenvolvidas das periferias (Frank, 1971; Wallertein, 1990); e, por fim, as teorias e políticas de desenvolvimento local com enfoque no modelo territorialista e potenciação dos recursos locais (Stohr, 1981; Reis, 1994; Cristóvão, 1994). Mas apresentemos, ainda que de modo sintético, as diversas teorias sobre o desenvolvimento.

\subsection{A teoria (neo)liberal do crescimento e da modernização}

Até aos anos 60 e de novo desde os anos 90 do século passado, tem predominado uma conceção evolucionista do crescimento económico que, sustentada pelas premissas da economia liberal defendida por Adam Smith, assumia uma visão assente no crescimento ilimitado através da lei da oferta e da procura, suscetível de alcançar um progresso económico e uma equilíbrio entre os indivíduos a operar na esfera do mercado. É certo que outros autores clássicos liberais, não partiIhando o otimismo de Smith, assumiam a tese de um crescimento limitado devido, por exemplo, ao facto de recursos como a terra serem limitados, como lembrava Ricardo, ou porque a população crescia exponencialmente mais que o produto, como alegava Malthus (in Silva e Cardoso, 2005: 27). Estes pressupostos viriam a ser abalados com a emergência da crise dos finais dos anos 20, nomeadamente o crash da bolsa de Nova lorque, a que acrescia o relativo sucesso da revolução soviética que conhecia um crescimento económico aparentemente não perturbado pela referida crise. Tal situação crítica, agravada com a depressão dos anos 30, deu lugar ao aparecimento da teoria keynesiana que, criticando algumas premissas liberais em torno da lei da oferta e da procura e estimulando uma política expansionista do emprego, viria a estar na base da recuperação das economias ocidentais nomeadamente no pós-Segunda Guerra Mundial.

Porém, as teorias liberais viriam a retomar com força na segunda metade do século XX nomeadamente através das teorias económicas do crescimento unilinear e faseado de Rostow (1960), o qual avançou igualmente a teoria liberal da modernização na base da transferência da técnica, da mudança de mentalidades e lideranças. Para Rostow (1960), as sociedades, para se desenvolverem, além de preencherem certos requisitos (demográficos, tecnológicos e de investimento de capital), deveriam possuir certas propensões tais como a de progredir e consumir, desenvolver e aplicar a ciência, não podendo fugir de passar pelas diversas fases desde o estádio tradicional, passando pelas fases de preparação para o arranque e de arranque, até outras a caminho da maturidade ou mesmo maduras e de

4 A variante liberal malthusiana propunha o casamento tardio e abstinência sexual para diminuir a população face à escassez de recursos ou ainda o corte nas prestações sociais para diminuir o Estado Social e incrementar a iniciativa privada e o investimento e, deste modo, revitalizar a economia. 
abundância, como seriam já as sociedades norte-americana e europeia ocidental. Além disso, segundo esta teoria liberal, as trocas entre países mais desenvolvidos e menos desenvolvidos assentariam no princípio das vantagens comparativas, em que todos ganhariam.

Por sua vez, estes economistas liberais, tal como referem Silva e Cardoso (2005), tiveram suporte noutras áreas, designadamente as teorias evolucionista, difusionista e assimilacionista, na antropologia e na sociologia, tendo nesta como arautos Parsons (1988), Hoselitz (1982) e outros, teorizando em torno das variáveis-padrão alternativas expressas nos modos de orientação dos atores, opondo uma comunidade ou sociedade tradicional a uma sociedade moderna industrial, sendo aqui de destacar a passagem de relações, normas e valores particularistas, baseadas no parentesco ou no clientelismo, para outras de caráter universalista, baseadas no mérito ou na busca da (auto)realização.

\subsection{Teoria neoinstitucional}

Apesar da recomposição no pós-ll Guerra Mundial, das melhorias e conquistas sociais nos chamados trinta 'gloriosos' anos, a evolução do sistema mundial, nomeadamente durante os séculos XIX e XX, não diminuiu o fosso entre países e regiões à escala mundial, situação esta que nos anos 60 e 70 do século XX provocou, a par da resposta liberal, uma nova resposta teórica conhecida por escola neoinstitucional, inspirada por autores como Seers (1969), Myrdal (1970, 1974) e, mais tarde, Sen (1999), os quais não só criticaram determinados pressupostos (neo)liberais (equilíbrio e evolução linear), como construíram uma nova corrente alternativa reformista que, indo ao encontro dos problemas concretos dos países e regiões subdesenvolvidas (atraso, explosão demográfica, desigualdades regionais, exclusão social, desemprego, discriminação étnica), possibilitasse uma melhoria de condições de vida. Ora, uma tal perspetiva progressista em termos económico-sociológicos exigiria não só uma maior participação dos povos, como uma ação mais interventiva dos estados nos países em vias de desenvolvimento, uma programação institucional indicativa e gradual, capaz de corrigir as distorções da própria economia de mercado e, assim, superar o 'círculo vicioso' da pobreza e do subdesenvolvimento. Como referem Silva e Cardoso (2005), contrariamente à tradicional posição da ortodoxia positivista da economia convencional que, com base na distinção entre factos e valores, afirma a ciência como campo isento ou neutro de valores, estes autores consideram justamente a esfera axiológica como um dos fundamentos e objetivos da sua economia neo-institucional, distinguindo, mas não separando, ciência e valores, juízos de facto e juízos de valor. 


\subsection{Perspetiva (neo)marxista e as teorias da dependência e centro-periferia}

Na ótica marxista, dada a contradição principal do sistema capitalista (produção social e apropriação privada) e as relações de dependência, designadamente financeira e tecnológica, dos países periféricos face aos países desenvolvidos, só é possível uma estratégia de desenvolvimento equilibrado desde que se socializem os meios de produção e, no quadro de uma via socialista, seja abolida a exploração da força de trabalho.

Tal como salientam Silva e Cardoso (2005), subjacente à visão marxista acerca do desenvolvimento encontra-se a própria teoria do valor do trabalho, única fonte de riqueza, na medida em que o capital é produto da soma das mais-valias acumuladas e não pagas ao trabalhador e na medida em que o próprio progresso tecnológico está incorporado no processo de produção.

Uma das consequências do processo de acumulação e centralização do capital a nível mundial seria a exploração e dominação dos países e regiões periféricas pelos países e regiões centrais, em que, segundo Lenine $(1971)^{5}$, o imperialismo se explica a partir das contradições entre a necessidade de expansão do capitalismo e o subdesenvolvimento das regiões atrasadas.

$\mathrm{Na}$ esteira da influência marxista e doutras correntes progressistas, começaram a ganhar corpo, sobretudo a partir dos anos cinquenta e sessenta do século XX, as teorias da dependência (Prebisch, 1963; Furtado, 1961; Frank, 1961; Cardoso e Falleto 1970) e do centro-periferia (Wallerstein, 1990; Santos, 1985; Fortuna, 1987), as quais refutam as teorias liberais e do crescimento nomeadamente de Rostow (1960), assim como os postulados parsonianos. As teorias da dependência, imbricadas e sustentadas em estudos concretos designadamente em países da América Latina, sustentavam que as causas do subdesenvolvimento dos países e regiões periféricas estavam estreitamente interligadas com o desenvolvimento dos países do centro desde a época da colonização ocidental, ou seja, a partir da expansão do capitalismo mercantil nos séculos XV-XVI. Tal como sustenta Frank (1961: 17), "antes de existir desenvolvimento, não existia subdesenvolvimento".

Quer pelos teóricos da dependência, quer pelos teóricos do centro-periferia, o capitalismo é definido fundamentalmente como comércio ou troca desigual baseada na divisão internacional do trabalho, em que a estrutura colonial-mercantil estaria na base da explicação da dependência e da relação centro-periferia.

5 Silva e Cardoso (2005) notam as diferentes posições analíticas entre Lenine (1971) e Rosa Luxemburgo (1967) sobre o imperialismo: enquanto na perspetiva de Luxemburgo (1967), a intensificação da exploração e dominação do sistema na fase imperialista seria inerente à lógica do capitalismo, para Lenine (1971), o imperialismo seria uma fase superior do desenvolvimento do capitalismo, a qual implicaria a formação de monopólios, fusão dos capitais bancário e industrial, exportação de mercadorias e de capital, divisão territorial do mundo com o avanço e o domínio dalguns países e regiões situadas no centro sobre outras situadas na periferia, mantidas em atraso e dependência. 


\subsection{0 modelo territorialista e de desenvolvimento local-regional}

Diversos autores (Stöhr, 1981; Pérez-Yruela et al., 1994 e, em Portugal, Lopes (1980), Amaro (1991) e Reis (1992, 1994), insatisfeitos com as teorias macroeconómicas e macro-sociológicas sobretudo no campo liberal e neoliberal, mas também e, em certa medida, no campo neomarxista, têm vindo a sustentar, pelo menos numa estratégia de curto-médio prazo, que o mais recomendável para diminuir as assimetrias regionais e os fenómenos de pobreza e exclusão social será apostar no desenvolvimento de caráter local e regional, tendo por base o território e seus recursos endógenos, dando assim lugar a um modelo designado de territorialista ou de desenvolvimento local. Se é certo que os constrangimentos económicos e políticos no atual quadro da globalização são sérios obstáculos ao potenciar do desenvolvimento local e regional, os defensores deste modelo, nomeadamente Reis (1992) e Pérez-Yruela et al. (1994), partem do pressuposto de que os atores locais e regionais, desde que preencham um mínimo de condições ou requisitos (densidade demográfica, bases técnico-económicas mínimas, organização, entorno institucional), estão em condições de explorar as oportunidades e potenciar o desenvolvimento local e regional. Esta abordagem parte não só do pressuposto de que os diferenciados territórios e seus agentes económicos e sociais (empresas, sindicatos, associações) detêm, em regra, recursos, capacidade de inovação e nichos de mercado para os seus produtos especíicos locais, como também, se organizados e funcionando em rede, podem inserir-se nos mercados globais (cf. Giménez, 1996; Villasante, 1999; Ferrão, 1999; Monteiro, 2004). Segundo Bailly (in Silva e Cardoso, 2005: 55-56), para que o modelo territorialista surta efeitos, não só em termos de desenvolvimento local como também de redistribuição mais equitativa do produto, o modelo de desenvolvimento local e regional deve ter presente determinados princípios, a saber: (i) o princípio da equidade territorial; (ii) o princípio da equidade social; (iii) o princípio do desenvolvimento durável e sustentado; (iv) o princípio da responsabilidade territorial; (v) o princípio da justiça ambiental no tocante aos espaços.

Contrariamente aos modelos macroeconómicos e macrosocietais em que são acionados instituições e mecanismos a nível central na mira de se difundirem efeitos pelo territórios locais, este modelo assenta num desenvolvimento pela base, o que implica mobilização de recursos, nomeadamente humanos, de preferência numa base associativa, quer em espaços urbanos, mais concretamente em pequenas e médias cidades, quer em espaços rurais que, não obstante a proximidade dos atores, apresentam amiúde dificuldades de associação e mobilização por conjugação de diversos fatores endógenos e exógenos, sobretudo num contexto de minifúndio rural. 


\section{Território e demografia: o Norte, Braga e Barcelos}

As atuais sociedades modernas, particularmente as ocidentais, sofrem um declínio demográfico considerável, também visível nas últimas décadas em Portugal, ainda que num ritmo menos acelerado e num quadro de diferenciação regional. O Norte de Portugal, nomeadamente o Minho, que nas décadas de 1960 e 1970 conheceu fortes perdas populacionais devido a um intenso êxodo rural e, sobretudo, a migrações maciças para a Europa (França e Alemanha) (32\% em Braga e 33\% em Viana do Castelo), recuperou no distrito do Porto e, sobretudo, no distrito de Braga: 16\% entre 1971 e 1981, 16\% entre 1991 e 2001. (INE, Censos 2001 e 2011). Entre 2001 e 2011 constata-se um aumento de 2,0\% da população residente em Portugal, que se deve, em grande parte, à afluência de imigrantes africanos e do leste europeu. O Norte, denso do ponto de vista populacional, apresenta entre 1991 e 2001 um ganho de população na ordem de 6,0\%; contudo, em 2011, surge estagnado por comparação com 2001.

Barcelos localiza-se na NUTS Cávado e, devido à sua proximidade geográfica, é interdependente e semelhante a municípios vizinhos (Braga, Famalicão e Guimarães), particularmente em termos sociodemográficos e económicos, diferindo ao mesmo tempo de outros ${ }^{6}$. Difere particularmente dos municípios do interior do Minho e, mais amplamente, da região e do país como um todo. $\mathrm{Na}$ sub-região Cávado, Barcelos ${ }^{7}$ faz parte do quadrilátero urbano, juntamente com Braga, Guimarães e Famalicão; constitui um dos quatro municípios mais dinâmicos da sub-região. Esta região prolonga-se a norte pela sub-região do Alto Minho (NUTS Alto Minho) e a sul pela NUTS Ave. Os referidos quatro municípios e Viana do Castelo, a nível populacional, absorvem cerca de $64 \%$ da população total dos 24 concelhos que compõem as três NUTS - Alto Minho, Cávado e Ave (INE/AERN, 2017, edição de 2018).

6 Por exemplo, comparando a densidade demográfica das quatro cidades do quadrilátero urbano (INE/ AERN, 2017, edição de 2018), nomeadamente Braga (989 hab/km2), Guimarães $(636,2)$, Famalicão $(654,3)$ e Barcelos $\left(308,8 \mathrm{hab} / \mathrm{km}^{2}\right)$, Barcelos é a que apresenta menor densidade populacional, sendo que em Braga está localizado o maior campus da Universidade do Minho e, por isso, para além de outros fatores de atração, torna-se numa vantagem competitiva.

7 No que concerne à caracterização geodemográfica de Barcelos, é importante assinalar que o município de Barcelos, com uma área de $317,3 \mathrm{~km}^{2}$, distribuída por 89 freguesias na anterior configuração (61 de acordo com a reestruturação administrativa de 2012/13, Lei n. ${ }^{\circ}$ 22/2012 de 30 de maio e Lei n. ${ }^{\circ} 11-\mathrm{A} / 2013$ de 28 de janeiro) e 876 lugares, com uma população de 120391 pessoas e uma área média de 4,26 km² por freguesia, apresenta-se como o maior de todos os municípios do distrito de Braga em área geográfica (Censo 2011). 
Figura 1: Representação geográfica do concelho de Barcelos (na NUTS Cávado)

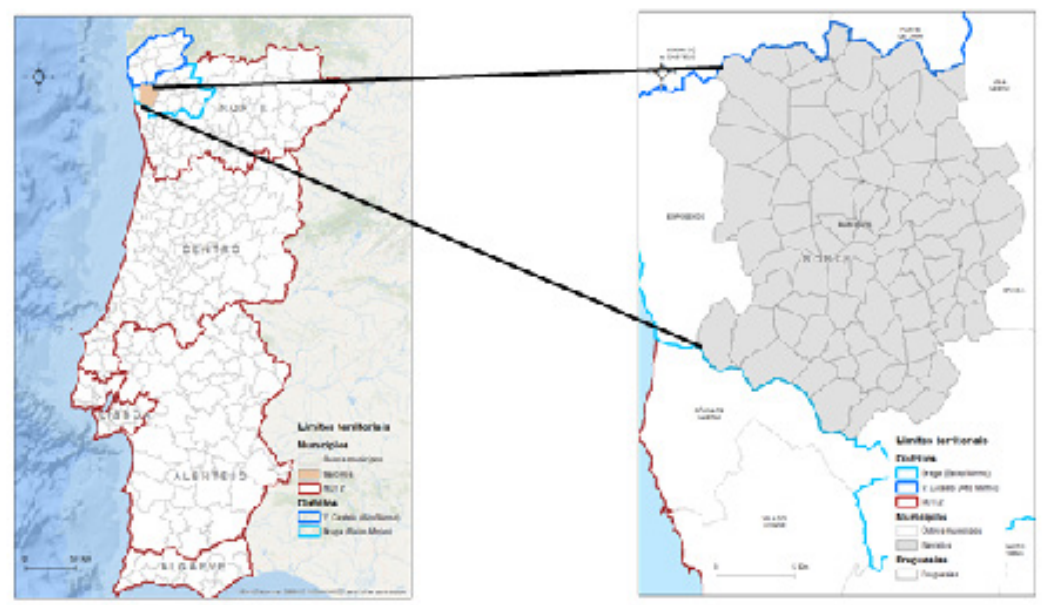

Entre outros índices denotativos do nível de qualidade de vida, há que considerar os índices de envelhecimento ${ }^{8}$ e dependência ${ }^{9}$. Mais especificamente, no seio da região Norte, o índice de envelhecimento evolui de 60 em 1993, para 114 em 2011, e para 146 em 2017. Nas NUTS Ave e Cávado, que apresentavam um baixo índice de envelhecimento em 1993 (45 e 46 respetivamente), este evolui para 96 e 87 respetivamente, atingindo em 2017 os valores de 135 e 122 respetivamente. Ou seja, o índice de envelhecimento da população das NUTS Ave e Cávado, em vinte e quatro anos, quase que triplicou. A NUTS Alto Minho apresenta-se ainda mais enveIhecida, em que o índice de 94, em 1993, evolui para 175 em 2011, atingindo o valor de 215 em 2017 (INE, AERN 2017; Censos 2001 e 2011). Por isso, pode inferir-se que o índice de envelhecimento da população tem aumentado significativamente na região Norte, destacando-se particularmente nas sub-regiões Alto Trás-os-Montes, Douro e Minho-Lima, com 250, 176 e 175 respetivamente em 2011, e 294, 221 e 215 respetivamente, em 2017, enquanto nas regiões do litoral, desde o Porto até às zonas industriais do Cávado e Ave, o índice evidencia-se consideravelmente mais baixo, para intervalos de 82 e 87 em 2011, e 121 e 128 em 2017 (INE/AERN, 2017).

8 Índice de envelhecimento - número de indivíduos com 65 anos ou mais a dividir pelo número de indivíduos entre 0 e 14 anos (resultado multiplicado por 100).

9 Índice de dependência de idosos - relação entre população idosa e a população em idade ativa, definida habitualmente como o quociente entre o número de pessoas com 65 anos ou mais e o número de pessoas com idades compreendidas entre os 15 e os 64 anos (expressa-se habitualmente por 100 pessoas com 15-64 anos).

Índice de dependência total - Relação entre a população jovem e idosa e a população em idade ativa, operacionalizada pelo quociente entre o número de pessoas com idades compreendidas entre os 0 e os 14 anos conjuntamente com as pessoas com 65 ou mais anos e o número de pessoas com idades compreendidas entre os 15 e os 64 anos. 
Juntando as taxas de natalidade aos índices de envelhecimento, podemos também fazer algumas comparações adicionais com o concelho de Barcelos, tendo por fonte os dados do INE: Censos de 2001; AERN, 2017; Estatísticas Demográficas e PORDATA.

Em relação à taxa bruta de natalidade, o concelho de Barcelos, em 2001, apresentava um índice superior (12,7\%o) à do território nacional $(10,9 \%$ ), assim como à da Região Norte (11,3\%). Quando se avança até 2011, a natalidade em Barcelos apenas supera ligeiramente $(8,9 \%$ ) a da região Norte $(8,6 \%$ ). Já em 2017 , no conceIho de Barcelos nasce-se menos (7,2\%o) do que na média nacional $(8,4 \%$ ).

Em relação ao envelhecimento, a análise dos dados relativos aos municípios do distrito de Braga, incluindo Barcelos, permite inferir conclusões semelhantes às da região mais ampla do Norte: os municípios menos densos do interior apresentam índices mais elevados de envelhecimento, enquanto outros mais industrializados e litorais revelam índices menos elevados ${ }^{10}$. De facto, a região do Minho sofreu, durante as últimas décadas, profundas transformações demográficas, sociais, económicas, políticas e culturais, apresentando hoje uma configuração morfológica, territorial, económica e sociocultural bem diferente em relação aos anos 1970, o que implica assumir uma perspetiva pluridimensional e pluricausal, na melhor tradição weberiana, e com um enfoque compreensivo e explicativo situacional.

Atendendo agora aos aspetos demográficos e socioeconómicos, certamente para este resultado convergiu algum crescimento económico resultante do investimento económico, aliado a uma dinâmica dos agentes económicos e sociais, graças à união de vários fatores de atração derivados das atividades industriais, de construção e de serviços e dos respetivos fluxos laborais e estudantis nos principais centros urbanos dos vales do Minho e do Lima (Viana do Castelo e Ponte do Lima) e sobretudo do Ave e do Cávado (Barcelos, Famalicão, Guimarães e sobretudo Braga).

A sub-região com maior crescimento populacional entre 1991 e 2001 foi a NUTS Cávado, crescendo 11,2\%, que já entre 1981 e 1991 havia registado o maior dinamismo populacional de entre as NUTS III do Norte, crescendo 7,4\%, surgindo Barcelos como um dos municípios que mais crescimento populacional apresenta na referida NUTS (década 1991-2001), para o qual contribuíram as elevadas taxas de natalidade registadas $(12,7 \%$ o e o facto de as taxas de mortalidade na NUTS do Cávado serem das mais baixas (7,3\%o) (INE/Censos 1991 e 2001/PORDATA).

Em relação à evolução demográfica em Barcelos, entre 1991 e 2001 e entre 2001 e 2011, a Tabela 1 dá-nos uma imagem do crescimento e rejuvenescimento demográficos. Segundo estes censos, a população residente no município de

10 Ainda que persista bastante por investigar acerca da região Norte de Portugal e, em particular, sobre o Minho, hoje em dia já existe um considerável grau de conhecimento sobre esta região, que diversos estudos, por parte de cientistas sociais oriundos nomeadamente da sociologia, da antropologia e da economia, têm proporcionado. Com efeito, é numericamente significativa a investigação realizada. Ainda que não seja exaustiva, por exemplo, a base de dados dos Serviços de Documentação da Universidade do Minho confirma essa ideia. Do ponto de vista demográfico e sociológico, é ainda de referir o relevante estudo realizado por uma equipa de investigadores na Universidade do Porto, coordenado por Gonçalves (2007). 
Barcelos aumentou em média cerca de 916 habitantes por ano entre 1981 e 2001, traduzindo-se num aumento populacional de 18323 habitantes (16\%) nesse período. Para além das razões ético-religiosas e de outros fatores, o aumento populacional nas décadas de 1990 e 2000 deve-se também ao retorno de emigrantes e à retenção de imigrantes, ao aumento da população escolar no ensino superior e inclusive a um certo dinamismo empresarial, nomeadamente nos setores têxtil, do calçado e da cerâmica.

Entre 2001 e 2017 Barcelos apresenta uma tendência de perda de população, com menos 1705 habitantes (-1,4\%) entre 2001 e 2011, e entre 2011 e 2017 perdendo mais 3384 pessoas, provavelmente devido à saída (forçada) em consequência da crise.

Tabela 1: Evolução demográfica em Barcelos (1981 - 2017)

\begin{tabular}{|l|l|l|}
\hline Censo & Número de residentes & Variação (\%) \\
\hline 2017 & 117007 & $-2,8(-3384$ habitantes $)$ \\
\hline 2011 & 120391 & $-1,4(-1705$ habitantes $)$ \\
\hline 2001 & 122096 & 9,3 \\
\hline 1991 & 111733 & 7,7 \\
\hline 1981 & 103773 & $1981(=100 \%)$ \\
\hline
\end{tabular}

Fonte: INE, Censos de 1981, 1991, 2001, 2011; AERN, 2017.

Mas a situação atual é outra. Além de apresentar perda de população, no balanço entre natalidade e mortalidade, Barcelos não é exceção em relação aos resultados das NUTS do Norte e do país, em que o número de óbitos $(7,7 \%$ o) supera o dos nascimentos (7,2\%o) (INE/AERN, 2017/PORDATA).

Em relação à distribuição da população residente por faixas etárias, verifica-se que, em 2001, Barcelos tem 45487 habitantes com menos de 25 anos, correspondendo a 37,3\% da população, mas em 2011 diminui para 29,6\%, e, em 2017, Barcelos conta nessa mesma faixa etária apenas 30083 indivíduos, que representam 25,7\% da população barcelense, diminuição essa que se deve à baixa natalidade. Ou seja, Barcelos, que em 2001 era um município maioritariamente jovem (37,3\% tinha idades entre 0 e 24 anos), pelo censo de 2011 apresenta uma descida no rejuvenescimento, constatando-se essa mesma tendência de descida em 2017. No entanto, o grosso da população, ou seja, quase $57,3 \%$ situa-se atualmente na ampla faixa etária dos 25 aos 64 anos. Estes valores são superiores aos da generalidade das restantes regiões continentais e rivalizam com os dos municípios mais jovens do 
Vale do Cávado e os dos municípios do distrito de Braga, apesar de seguirem a tendência de envelhecimento da população em Portugal.

Em jeito de síntese, poder-se-á dizer que as estruturas demográficas em Barcelos - finalmente não muito diferentes das demais cidades do quadrilátero urbano - caracterizam-se por uma proporção relativamente elevada de população jovem, uma tendência de renovação que, no entanto, parece diminuir devido ao decréscimo demográfico, refletindo-se já na redução dessa população jovem. É de assinalar que a população com mais de 65 anos (19 934) ultrapassa com uma margem ampla a população com menos de 15 anos (15 452). O crescimento demográfico é co-estruturado, entre outros fatores, pelo investimento de capital, pelos fluxos de mão-de-obra e circulação e retenção, ainda que temporal, de estudantes, como já atrás referido.

\section{Economia em crescimento mas dependente: um modelo esgotado}

Na região de Barcelos, apesar de algumas melhorias, sobretudo nos transportes rodoviários, basicamente as estruturas de transporte mantêm-se, ainda que, dada a construção algo desordenada, é cada vez mais difícil planear uma rede de transportes ferroviários e rodoviários de maneira a servir as populações, não apenas as mais isoladas mas inclusive as residentes no quadrilátero urbano de Famalicão, Guimarães, Braga e Barcelos ${ }^{11}$. O transporte ferroviário conheceu desde 2001 uma melhoria com a introdução, primeiro, do Intercidades e, posteriormente, do Alfa que liga Lisboa a Braga, mas com acentuada secundarização das ligações a Viana do Castelo e a Valença' ${ }^{12}$. Com esta política de desinvestimento na linha férrea articula-se um maior espaço de manobra para os setores ligados ao transporte e às infraestruturas rodoviárias, que têm conseguido retirar dividendos dessa política, não apenas nas vias secundárias, mas inclusive na construção de vias rápidas e autoestradas.

Quanto à taxa de atividade, verifica-se que entre 1981 e 2001 há um aumento considerável de população ativa, a nível quer nacional (de 42,5\% a 48,2\%), quer

\footnotetext{
11 Em 2008 foi criado o quadrilátero urbano, formado pelas cidades de Braga, Barcelos, Guimarães e V. N. de Famalicão, com o objetivo de promover a competitividade e a internacionalização. Contudo, a ideia de constituir uma única empresa de transportes urbanos das referidas quatro cidades também não vingou, o que denota a dificuldade em se superar a lógica territorial que parte de cada município. Os municípios da região, em geral, e o Alto Minho, em especial, nesse setor dos transportes, ainda se apresentam mais desarticulados, com enormes transtornos de mobilidade, e até de isolamento, para as populações de localidades mais periféricas. Neste quadro, a única exceção é a da maior densidade de ligações proporcionada pela rede de transportes urbanos de Braga (TUB).

12 Contudo, é de assinalar positivamente a eletrificação da linha do Minho, entre Nine e Viana do Castelo, com um investimento de 16,5 milhões de euros (Nota de Imprensa do Gabinete do Ministro das Infraestruturas e da Habitação, 15.7.2019). De resto o desinvestimento estatal verificou-se em toda a região Norte, nomeadamente nas linhas férreas de pequeno percurso, resultando em encerramentos de linhas e menor frequência de comboios, com a agravante da entrega a privados do património ou de certos espaços (apeadeiros), para exploração particular por empresas rodoviárias.
} 
regional (de 42,4\% a 48,1\%) (Gonçalves 2007), motivado principalmente pela entrada maciça das mulheres no mercado de trabalho. $\mathrm{O}$ aumento de ativos pode complicar o problema do desemprego na medida em que, em tempos de crise, pode ser mais difícil, diminuir ou, pelo menos, estancar a subida do desemprego, que se cifrava em 6,4\% em 2001, 13,6\% em 2011 e 15,2\% em janeiro de 2014 (INE e Eurostat, 2014), baixando todavia para 6.7\% em 2018 (Inquérito ao Emprego, INE, 2018). As transformações no perfil da mão-de-obra indicam a centralidade que assume hoje a questão das competências e da capacidade da designada aprendizagem ao longo da vida, um dos dilemas que esta região, e particularmente o município de Barcelos, enfrentam.

No que respeita à população industrial no distrito de Braga, os concelhos de Guimarães, Famalicão, Braga e Barcelos absorviam, segundo Ribeiro (1984: 33-34), 90\% da mão-de-obra industrial em 1971 e 79\% em 1981, o que, para além de denotar alguma deslocação intermunicipal, representa uma situação desigual na distribuição territorial com discrepante dualidade em relação aos concelhos do interior $^{13}$. A norte do Porto, e a nível da região minhota, são basicamente estas cidades mais litorais do norte do país, as que, para além de reterem quase $80 \%$ da população, continuam sendo polos de atração e veículos de indução de crescimento económico, em contraposição a outras cidades e vilas do interior, que se confrontam com uma desertificação progressiva, e uma regressão por parte de espaços rurais de perda demográfica e económica (com $40 \%$ dos centros urbanos com dimensões de 2000 a 5000 habitantes). A tendência de perda é tanto maior quanto mais avançamos para áreas do interior do Minho e, em particular, do Alto Minho (cf. Silva e Cardoso, 2003: 203).

A ausência de indústrias de ponta, assim como a baixa diversificação industrial na região minhota, principalmente na NUTS Minho-Lima, agravada por outros problemas como a baixa produtividade, a falta de criatividade e a "pulverização" dos setores das indústrias transformadoras, debilitam a economia da região, incluindo obviamente Barcelos, tornando-a altamente vulnerável a impactos externos. Segundo diversos especialistas, particularmente Ribeiro (1984), Silva e Ribeiro (2000), Silva e Cardoso (2003), este modelo de acumulação, tal como refere Cabral (1979), que teve uma razão económica devido ao diferencial salarial e a uma industrialização difusa em benefício dos industriais e, em complemento, aos exíguos rendimentos das famílias camponesas mais pobres, e que prevaleceu, está hoje em vias de se esgotar, como o demonstram os estudos de Ferreira (1993) e M. Silva (2000).

Atualmente, no quadro do processo de globalização e da competitividade internacional, principalmente pela importação de produtos têxteis de outros países e, em particular, da Ásia, a indústria têxtil está a atravessar uma crise preocupante,

13 Em relação ao distrito de Viana do Castelo, verificou-se uma tendência semelhante: 65\% entre Viana do Castelo e Ponte do Lima em 1971 e 59\% em 1981. 
dado que o tecido empresarial, não se tendo, na sua maioria, modernizado, está determinado predominantemente pela presença maioritária de médias e, sobretudo, pequenas e microempresas familiares, com apenas 0,1\% de empresas com mais de duzentos trabalhadores.

Vendo agora o índice do poder de compra per capita, ${ }_{1}^{14}$ verificamos que, nesta região e entre 2011 e 2015, ele se situava abaixo da média nacional (índice 100): na NUTS do Norte com 89,2 em 2011 e 92,1 em 2015; no Alto Minho com 77,6 em 2011 e 79,9 em 2015; no Ave com 79,4 em 2011 e 84,5 em 2015; no Cávado com 85,9 em 2011 e 88,8 em 2015; em Barcelos ele passa de 72,6 em 2011 para 77,7 em 2015 (cf. Estudo sobre o Poder de Compra Concelhio ${ }^{15}$, PORDATA/INE, 2017). Estes valores evidenciam que, em média, o poder de compra é desigual, não só face ao que existe em grandes centros urbanos como Lisboa e Porto (214,5 e 161,4, respetivamente, em 2015), mas também na própria região, nas NUTS do Norte e na do Cávado, onde Barcelos se insere. O referido índice apresenta valores ainda mais baixos nos municípios do interior, onde muitos são os habitantes rurais que praticam a pluriatividade, tornando-a uma modalidade muito presente no país e no próprio município de Barcelos, tendência já realçada por Silva (1998). Tal modalidade constitui um dado muito importante para compreender o relativo baixo grau de conflitualidade social num contexto de industrialização difusa, ao compará-lo com o de outras regiões e cidades de áreas metropolitanas. Esta procura de pequenos rendimentos oriundos de diversas atividades, sobretudo para os que se mantêm no mundo rural, tem a vantagem de atenuar os efeitos dos riscos do desemprego ou da precariedade laboral nos setores da indústria e dos serviços.

\section{Um território de desigualdades}

Depois de apresentada uma breve visão sociodemográfica da região Norte, das NUTS Ave e Cávado e, mais concretamente, do município de Barcelos, importa agora dar conta de outras dimensões e aspetos das desigualdades no desenvolvimento no que respeita à segurança social, à habitação e às infraestruturas e equipamentos, por um lado, e à cultura e à educação, por outro.

14 O Indicador per Capita do poder de compra (IpC) pretende traduzir o poder de compra manifestado quotidianamente, por habitante, nos diferentes municípios ou regiões, tendo por referência o valor nacional. 150 referido estudo (EPPC) do INE caracteriza os municípios portugueses sob o ponto de vista do poder de compra, a partir de um conjunto de indicadores resultantes de um modelo de análise fatorial: o Indicador per Capita de poder de compra (IpC), a Percentagem de Poder de Compra (PPC), indicador derivado do IpC, e o Fator Dinamismo Relativo (FDR). Aqui apresentamos apenas a Indicador per Capita de Poder de Compra, que reflete a importância do poder de compra manifestado quotidianamente em cada município ou região no total do país para o qual a PPC assume o valor de $100 \%$. 


\subsection{Infraestruturas e equipamentos, desemprego e saúde}

Na tentativa de avaliar a situação da região e, em particular a de Barcelos, no que concerne a vários indicadores sociais, a primeira observação que se reconhece é que, não obstante consideráveis melhorias nas últimas duas décadas em infraestruturas e equipamentos, nomeadamente nos municípios do referido quadrilátero urbano, aquelas não são suficientes e adequadas para as necessidades atuais. Por outro lado, tal como em outros países e regiões, também na região do Minho verifica-se uma desigual distribuição territorial de infraestruturas, equipamentos e recursos humanos. Isso significa que, apesar das continuidades entre o rural e o urbano, persistem algumas desigualdades e desequilíbrios socio-espaciais.

Retomando a questão do desemprego, sabemos que esta realidade tem sido bem severa, principalmente nos anos de crise, em que o Norte apresenta uma taxa superior à do país, tendo o índice duplicado em relação a 2001, nomeadamente na NUTS Cávado, onde Barcelos se integra. O município de Barcelos, em 2011, apresenta cerca do triplo de desempregados em relação a 2001 (de 4,3\% para 12,1\%) (Cardoso, 2012: 117), evidenciando em 2016 um maior índice de desemprego nas mulheres (15,4\%) comparado com o dos homens $(12,3 \%)$, o que vem confirmar estudos sobre segmentação sexual dos mercados de trabalho e das baixas remunerações (Marques, Silva e Veiga, 2006; Kovács e Casaca, 2008).

Os desempregados não são apenas pessoas adultas menos qualificadas, mas também o têm sido e cada vez mais os jovens, incluindo jovens qualificados: cerca de 30\% em 2011 têm idades inferiores a 25 anos. Para além disso, dada a tendência predominante do individualismo institucionalizado, assiste-se a uma crescente dualidade ou inclusive fragmentação dos mercados de trabalho, em que franjas cada vez maiores de jovens estão sujeitos a trabalhos precários e incertos, flexíveis e mal pagos ${ }^{16}$.

Considerando indicadores no sector da saúde, a região, assim como o resto do país, conheceu melhorias em infraestruturas, serviços e equipamentos desde os anos setenta e sobretudo desde o 25 de Abril de 1974 com a implementação do SNS, graças aos princípios da universalidade e tendencial gratuitidade do sistema de saúde pública, consagrados respetivamente nos artigos 63 e 64 da Constituição da República Portuguesa (CRP) de 1976 e desenvolvidos na Lei 56/79 do Serviço Nacional de Saúde. No entanto, estes princípios têm sido, senão revogados, pelo menos debilitados na sua execução prática por vários fatores que se prendem com a ineficiência e a lentidão de resposta do sistema (por exemplo, listas de espera para consultas de especialidade), a promiscuidade dos interesses públicos e privados, reforçando a medicina privada e os sistemas privados de 
saúde. De facto, tal como o evidencia S. Silva (2007), entre 1988 e 2004 verifica-se na região Norte uma ligeira redução do número de hospitais públicos por 100000 habitantes, enquanto aumentam os privados nas restantes sub-regiões, exceto em Trás-os-Montes, Douro e Minho-Lima onde não os há, e principalmente nas NUTS Grande Porto (de 0,9 para 1,2), Cávado (de 2,0 para 2,5) e Ave (de 0,2 para 0,6). Ou seja, entre 1988 e 2005 os hospitais públicos passam de 1,3 a 0,9 por 100000 habitantes (de 1,4 a 1,1 no país), enquanto os privados passam de 0,6 a 0,8 (mantendo-se nesse período em 0,9 no país).

Para além das deficiências gerais do sistema, ao avaliar a situação à escala nacional, regional e sub-regional, verifica-se uma acentuada desigualdade territorial e social no acesso a bens de saúde entre os grandes centros - Lisboa, Porto e Coimbra, que concentram a grande parte dos meios e de profissionais do setor, em particular, o pessoal mais altamente especializado - e as demais cidades e vilas do país. Esta lógica de concentração e desigualdade territorial à escala nacional e regional reproduz-se ainda de modo mais evidente entre a média ou mesmo a pequena cidade e as aldeias, sobretudo as mais afastadas dos hospitais e centros de saúde. Ou seja, o acesso à saúde está, por isso, não apenas dependente das condições socioeconómicas dos diferentes grupos/classes sociais e das características dos indivíduos, mas também da desigual distribuição territorial de infraestruturas e equipamentos, especialidades e pessoal de saúde, o que penaliza, como se acaba de assinalar, as populações residentes em zonas mais afastadas e isoladas geográfica e socialmente.

Em 2017 Portugal tinha 225 hospitais (114 privados e 111 do SNS, 4 dos quais em parceria público-privada), e o número de camas de internamento nos hospitais do Serviço Nacional de Saúde (SNS) passaram de 27086 em 2007 para 24050 em 2017, ou seja, os hospitais públicos perderam cerca de três mil camas de internamento numa década, enquanto os hospitais privados ganharam mais de 1700 camas, sendo, contudo, no SNS que se fazem quase $80 \%$ dos internamentos (Estatísticas da Saúde, 2017).

Se compararmos o número de hospitais por natureza institucional (público ou privado), verificamos que as NUTS Cávado e Ave, juntas, possuíam, em 2002, um total de 17 hospitais, 11 dos quais eram de natureza privada, passando em 2016 as referidas NUTS a possuir no seu território 18 hospitais, 14 dos quais privados. Ou seja, um aumento, neste caso, de 3 hospitais privados num intervalo de tempo de 14 anos (INE/Inquérito aos Hospitais, 2013 e AERN, 2017). Ainda na área da saúde, tendo em conta as tendências mais recentes, a situação tende a deteriorar-se com o encerramento de maternidades e centros de saúde e com a falta de investimento público no setor. No caso do município de Barcelos, ainda que ele não sofra dos problemas de pequenos municípios do interior, tem consideráveis carências no domínio da saúde: possuindo quatro hospitais, apenas um é público, cujo funcionamento deficitário obriga os cidadãos doentes a recorrer aos hospitais privados, com altos custos, ou a terem de ser reencaminhados para o hospital distrital, por falta de recursos ou de especialidades. 


\subsection{Segurança social e habitação}

Seguindo a tendência nacional ${ }^{17}$, também a região norte conheceu, entre 1981 e 2001, um considerável aumento da população não ativa, no segmento dos reformados ou dos pensionistas em geral: passaram de $16 \%$ no país (13,9\% na região Norte) em 1981 para 36,1\% no país (32\% no Norte) em 2001 (Gonçalves, 2007), sendo de 28,8\% na região em 2011 (INE, Censo 2011), o que se compreende graças à melhoria dos cuidados de saúde e ao aumento da esperança de vida.

Também nos indicadores relativos à segurança social, para além da discrepância das médias de gastos sociais face à média europeia ${ }^{18}$, na região do Minho evidenciam-se disparidades começando pela percentagem de pensionistas em relação à média nacional e no interior do Minho - em que a maior parte vive com baixas pensões. Por isso, as regiões com menos recursos, com cidadãos idosos com passados contributos curtos, baixos ou nulos, com pensões de velhice ou de subsistência como principal base de subsistência, apresentam um maior número de pensionistas que vivem com dificuldades (Tabela 2).

Tabela 2: Número de pensionistas por 100 habitantes

\begin{tabular}{|c|c|c|c|c|c|}
\hline & $1993^{*}$ & $1998^{*}$ & $2003^{*}$ & 2011 & 2017 \\
\hline Portugal & 22,9 & 24,4 & 24,3 & 28,2 & 29,7 \\
\hline Região & 20,9 & 21,4 & 22,2 & 26,8 & 28,8 \\
\hline Ave & 19,10 & 19,8 & 20,4 & 26,9 & 29,5 \\
\hline Cávado & 19,4 & 19,5 & 19,6 & 23,2 & 25,3 \\
\hline Barcelos & ---- & ---- & --- & 23,3 & 26,9 \\
\hline $\begin{array}{c}\text { Minho- } \\
\text { Lima/ Alto Minho }\end{array}$ & 25,5 & 26,1 & 27,2 & 30,7 & 32,0 \\
\hline $\begin{array}{c}\text { Grande } \\
\text { Porto }\end{array}$ & 19,5 & 20,5 & 21,5 & 26,8 & 28,9 \\
\hline
\end{tabular}

Fonte: Ministério de Segurança Social e Trabalho, Instituto de Informática e Estatística de Solidariedade (IIES), (*dados elaborados por Pinheiro, 2007), Anuário Estatístico da Região Norte 2011 e 2017.

17 O número de pensionistas em Portugal passou de 861 700, em 1975, para 2528800 em 2001, um aumento cujas razões têm sido analisadas por especialistas (cf. Carreira, 1996; Mendes, 2005; Gonçalves, 2007). É de notar que uma parte considerável destes inativos (pensionistas por velhice ou beneficiários de pensões de sobrevivência), nomeadamente em meio rural, só o são em parte, uma vez que eles continuam ocupados com a atividade agrícola e pastoril ou pecuária, donde retiram um complemento de rendimento ou, noutros setores, sobretudo no mercado de trabalho informal: por vezes como forma de passar o tempo, mas na maior parte dos casos por necessidade devido ao baixo valor das pensões.

18 Entre 1993 e 2003 os gastos sociais em Portugal tiveram um aumento, passando de 1547 para 3192 euros per capita, enquanto a média europeia passava, no mesmo período, de 4683 para 6880 euros por habitante (Eurostat). 
No entanto, o indicador mais importante para as condições de vida dos pensionistas é o valor médio mensal das pensões baseadas no trabalho associado ao setor primário ou outros setores de baixos salários, ou aqueles sem contribuições para a sua reforma. Entre 1993 e 2011, a pensão mensal média, em todas as regiões, aumentou bastante, embora esse facto deva ser ponderado com o aumento da inflação e do custo de vida, aos quais se acrescentam cortes consideráveis desde 2011 (Pinheiro, 2007; INE/AERN, 2017).

Relativamente à região do Minho observamos que, quer em 2011 quer em 2017, na NUTS Alto Minho, por cada 100 habitantes, cerca de um terço é pensionista, valor superior à média nacional (28,2\%) (Tabela 2). Pelo contrário, Cávado e Ave apresentam, para os mesmos períodos, valores inferiores ou a rondar a média nacional. Mas também aqui as assimetrias são fortes: nos concelhos de Terras de Bouro e de Vila Verde (Cávado) e de Vieira do Minho (Ave) os pensionistas situam-se no intervalo aproximadamente de $27-38 \%$ do total da população. As desigualdades também são evidentes quando se compara o valor médio das pensões: os pensionistas de Terras de Bouro (Cávado), Vila Verde (Ave) e Paredes de Coura (Alto Minho) recebem 2 431; 2665 e 1705 euros por ano, respetivamente, enquanto a média nacional se situa nos 2826 euros/ano (INE/AERN, 2017).

No que concerne à habitação, a região Norte apresenta, em termos de alojamentos clássicos, uma posição mais vantajosa em relação á media do país (cf. Pinheiro, 2007). Para além das migrações internas para o litoral, nomeadamente à procura de emprego, nas sub-regiões do Cávado e Ave, as facilidades de crédito para a aquisição de casa própria com bonificação de juro, para a posse de uma segunda casa com usos diversos contribuiu para o aumento de habitações. Para esta situação contribui o sentido arreigado de propriedade numa região tradicional de minifúndio, cujas diversas estratégias, desde a herança, o casamento e a emigração, se orientam no sentido de se conservar ou adquirir uma propriedade, começando por uma casa própria.

\subsection{Cultura e educação}

A cultura e a educação são indicadores relevantes para se aferir o estado de desenvolvimento de um país e, no nosso caso, a nível cultural, os contrastes permanecem. Por exemplo, o número de galerias de arte e espaços de exposições temporárias por 100000 habitantes, nas diferentes sub-regiões do Minho é inferior à média do país (10/100 000): NUTS Cávado com 5,4/100 000 habitantes e NUTS Ave com 5,6/100 000 habitantes, sendo exceção a NUTS Minho-Lima que apresenta, nos últimos anos, o valor 12,9/100 000 habitantes, e que é superior á média nacional. Quanto ao número de museus: se no Alentejo ronda os 9,4/100 000 habitantes e em Portugal os 4,7/100 000, no Alto Minho ronda os 5,2/100 000 (INE/AERN e 
PORDATA, 2017). Em relação a publicações de imprensa (jornais e revistas), as 19 publicações existentes, na NUTS Alto Minho, conseguem uma circulação de 631 661 exemplares, enquanto na Cávado as 44 existentes asseguram uma circulação de 7120020 exemplares e, na NUTS Ave, os 19 títulos chegam aos 792817 exemplares (INE/AERN, 2017). Em relação ao campo cultural, em Barcelos, não obstante algumas melhorias, graças não só à Câmara Municipal, mas também ao IPCA e a outros agentes culturais, há um longo caminho a percorrer para elevar o nível cultural da população barcelense.

Um outro fator que pesa no nível e na qualidade de vida dos cidadãos é a sua escolaridade. Uma primeira nota é que o sistema educativo português experimentou importantes transformações, nos últimos trinta anos, nomeadamente uma considerável diminuição do analfabetismo, tal como o comprovam vários indicadores de escolarização, particularmente durante as últimas 3 décadas.

Nas últimas décadas, principalmente desde 1970, primeiro, com as mudanças promovidas pelo ministério liderado por Veiga Simão (1970-1974) e especialmente desde o 25 de Abril de 1974 até 2011, Portugal registou um progresso educacional considerável do ponto de vista quantitativo e qualitativo: por exemplo, o analfabetismo caiu de $25,6 \%$ para 9,2\% em $2011^{19}$, destacando-se, ainda, a diminuição do abandono escolar entre os 10 e os 15 anos, nomeadamente de $12,5 \%$ para 2,7\%, o aumento da taxa de pré-escolarização no ensino público e privado de crianças entre os três e os cinco anos (de 41,7\% para 71,6\%), e o aumento das taxas de escolarização em todos os níveis de ensino (Resende e Vieira, 2003; Silva e Cardoso, 2013).

Apesar destes avanços, o desempenho educativo português apresenta hoje várias fragilidades quando comparado com o dos seus pares da União Europeia. Para além disso, o esforço de aproximação das metas traçadas no quadro da Agenda de Lisboa não foi conseguido, agravando-se este cenário quando se analisam os indicadores na escala regional, intrarregional e municipal.

Apesar dos progressos, Portugal apresenta uma taxa de analfabetismo superior à de outros países (9\% em 2001 e 6,8\% em 2011, INE/Censos). No que concerne à educação em termos regionais, a região do Minho apresenta uma heterogeneidade e desigualdade socioeducativas, sendo de salientar as taxas de analfabetismo. O distrito de Braga apresenta em 2001 uma taxa média de analfabetismo de 10,6\% , com variações internas por concelho desde 5,6\% em Braga até 16,6\% em Celorico de Basto, ficando Barcelos com a taxa intermédia de 7,6\% ${ }^{20}$. Já em 2011, a

19 No entanto, Portugal apresenta em 2011 uma taxa de analfabetismo na ordem dos 5,23\%, o que equivale a cerca de meio milhão de portugueses que não sabem ler nem escrever.

20 O distrito de Braga, ainda que tenha seguido uma tendência de baixa ao longo das últimas décadas, apresenta em 2001 e 2011, apesar de tudo, uma média superior à média nacional, ou seja, 10,6\% e 6,5\% respetivamente. Por exemplo, isso sucede em Celorico de Basto (16,6\%), Cabeceiras de Basto (16\%), Terras de Bouro (15,6\%) e Vieira do Minho (12,8\%); outros concelhos do distrito de Braga apresentam taxas de analfabetismo inferiores à média nacional, destacando-se por ordem decrescente, nomeadamente Vizela (7,9\%), Barcelos (7,6\%), Guimarães (7,4\%), Esposende (7,3\%), Vila Nova de Famalicão (6,7\%) e Braga (5,8\%). De modo 
situação, embora tenha melhorado em relação aos anteriores Censos (v.g., Braga com 3,4\% e Barcelos com 4,6\%), apresenta ainda elevados índices na ordem entre os 9 e 10\% nos concelhos interiores tais como Terras de Bouro, Celorico de Basto e Cabeceiras de Basto. Relativamente ao conjunto de cidadãos que, ou são analfabetos, ou sabem ler e escrever mas não obtiveram o grau do ensino básico, a sua proporção, no distrito de Braga era, em 2001, de 14,5\%; os que completaram o primeiro ciclo somam $36,7 \%$ do total; e os do segundo ciclo $17,6 \%$; em relação ao terceiro ciclo, a taxa alcançada pela população do distrito de Braga é de 11,7\%.

Quanto à educação pré-escolar, o número de educadores aumenta, passando de 2004 em 1995-96 para 5500 em 2005-2006 (INE, Estatísticas da Educação in Magalhães, 2007). Apesar deste aumento, dado como positivo, verifica-se, no entanto, uma distribuição irregular e insuficiente da oferta, principalmente no que respeita à falta de infraestruturas e de profissionais qualificados, estando coberta só em 39,4\% da região Norte por estabelecimentos pré-escolares públicos e privados. Em certas cidades, regista-se um fenómeno de sobreocupação como, por exemplo, nas cidades de Braga, Porto, Viana do Castelo, contrariamente a outras em que há uma subocupação (Alto Minho).

Em relação ao primeiro ciclo, tanto no país como na região, verifica-se entre 1995-96 e 2002-03 uma diminuição de escolas por não haver um número mínimo de alunos, o que comporta uma diminuição de docentes na região Norte, passando de 14640 em 1995-96 para 13381 em 2005-2006 (Magalhães, 2007). Esta situação conduz ao encerramento de escolas, o que se compreende pela queda demográfica, sentida particularmente nas aldeias do interior, que se veem privadas de uma das suas instituições fundamentais.

Quanto às escolas do $2^{\circ}$ e do $3^{\circ}$ ciclo do ensino básico (EB 2-3), estas apresentam taxas de cobertura diferenciadas e apoios desiguais, podendo dizer-se que, segundo os dados da Direção Regional da Educação do Norte (DREN), essas taxas são de $28 \%$ vs $42 \%$ em termos nacionais. A nível da região Norte e, em particular, na zona mais litoral, desde concelhos como V. N. de Gaia, Porto até Braga, verifica-se igualmente um aumento significativo do número de estabelecimentos do $2^{\circ}$ ciclo.

Quanto ao nível do ensino secundário, apenas $12,1 \%$ da população do distrito de Braga completou o ensino secundário: uma média inferior à média nacional de 15,7\% (cf. INE, Censos 2001), embora a situação atual seja mais favorável. Entre os trabalhadores assalariados, mais de $90 \%$ tinham o nível igual ou inferior ao $9^{\circ}$ ano ${ }^{21}$, enquanto este tipo de escolarização, em termos nacionais, situava-se em

mais acentuado, o distrito de Viana do Castelo conhece em 2001 médias que vão desde 7,1\% em Viana até 20,3\% em Arcos de Valdevez.

21 Segundo os resultados e comparações internacionais, confirma-se a acentuada concentração da população portuguesa nos níveis mais baixos de escolaridade (Benavente et al., 1996; Gomes et al., 2000). 
77\%, indicando um nível de formação escolar mais baixo nesta região (Ribeiro et al., 2000: 17; Silva e Cardoso, 2003: 208)22.

Ainda em 2011 era possível concluir que o número de estabelecimentos de ensino do $3^{\circ}$ ciclo (e de docentes) não tinha sofrido grandes alterações nos conceIhos portugueses desta região. Deste modo, quanto à dinâmica educativa a nível do ensino profissional no norte de Portugal, esta pode ser medida, em parte, pelo número significativo de Escolas Profissionais no contexto nacional: 38,7\% que, para além da sua expressão na sub-região do Grande Porto (32,6\%), assume importância também nas sub-regiões do Alto Minho (16,3\%) e do Ave $(15,1 \%)$.

Em relação à NUTS Cávado, a percentagem de jovens que seguem o ensino secundário ou o ensino pós-secundário, apesar de estar aquém do necessário e do desejável, é considerável: mais elevada no ensino secundário como expressão de um maior investimento em planos/trajetos escolares mais prolongados ${ }^{23}$, projetando-se alcançar o nível do ensino superior (universitário ou politécnico); menos significativo, ou inclusive residual, é o caso do ensino pós-secundário, enquanto expressão de 'opções' obviamente limitadas no sentido da procura e realização de planos escolares mais curtos e mais orientados para a profissionalização, com entrada no mercado de trabalho mais tardia, muitas vezes por não haver meios de se obterem qualificações mais elevadas e, sobretudo, pela urgência em se encontrar um emprego mais cedo.

\section{Notas finais}

O retrato sintético que se procura aqui dar da sociedade e da economia em termos regionais e, em especial, do concelho de Barcelos, demonstra que estamos perante uma região semiperiférica e uma economia de crescimento desigual e cada vez mais vulnerável. Por outro lado, os dados estatísticos do INE e a consulta de outras fontes e estudos apontam para situações de disparidades sociais, destacando-se o fator espacial, que associado às dinâmicas demográficas, constitui um fator co-determinante das desigualdades socioeducativas e culturais.

Os dados relativos a vários indicadores verificados nos municípios mais centrais, urbanizados e litoralizados apresentam-se algo mais satisfatórios que os dos municípios mais interiores e distantes dos principais centros urbanos minhotos. Tanto os dados relativos à NUTS Cávado, Ave, como os relativos à do Alto Minho, mostram uma correlação entre a proximidade de infraestruturas, equipamentos e

22 Neste campo Portugal tem o valor mais baixo: $17 \%$ de alunos contra uma média de $22 \%$ no espaço da OCDE. No entanto, o cenário apresenta-se mais preocupante se atendemos à percentagem de alunos que nem sequer alcançou o nível 1, revelando sérias dificuldades em usar a leitura como um instrumento efetivo para a extensão de conhecimentos e competências noutras áreas. Nesta situação encontram-se $10 \%$ dos alunos portugueses, sendo a média no espaço da OCDE de 6\% (ME 2002).

23 Isto reflete-se no aumento absoluto, mas não em percentagem, de docentes no ensino secundário na região Norte, passando de 35928 (68,3\%) para 40604 (52,9\%). 
recursos humanos acessíveis e disponíveis para as populações e, por exemplo, a frequência de graus de ensino mais elevados.

De facto, vários indicadores infraestruturais, económicos e sociais dão conta não só da situação de (semi)periferia do Norte de Portugal, concretamente da sub-região situada ao norte de Porto e, muito particularmente, nas zonas do interior do Minho, assim como dão conta das disparidades relativas e dos diversos tipos de desigualdades na região, e no concelho de Barcelos em particular, fruto de uma desigual distribuição territorial de infraestruturas, equipamentos e recursos humanos. Isso significa que, apesar das continuidades entre o rural (atrasado) e o urbano, persistem algumas desigualdades e desequilíbrios socio-espaciais.

Esta situação não pode ser entendida e explicada sem termos em conta as condicionantes históricas, sobretudo em termos económicos e político-culturais, agravadas por processos recentes de desagrarização ${ }^{24}$ e desindustrialização. Este persistente e relativo atraso não poderá ser contrariado, por um lado, se não se diversificam as atividades económicas, valorizando e modernizando a agricultura e, por outro lado, se não se fomentam outras atividades produtivas industriais e de serviços.

Alguns dos impasses e défices verificados podem seguramente ser superados com a criação de uma estrutura política regional, pelo que esta regionalização é um imperativo incontornável. Na esteira de Ribeiro (1984), Figueiredo (1985) e Silva e Cardoso (2003), poder-se-á dizer que o futuro da região passa por um enquadramento institucional no qual os poderes regionais seriam um suporte fundamental de desenvolvimento socioeconómico e cultural, o qual dependerá, por sua vez, de uma estratégia de aproveitamento dos recursos locais, numa lógica de forte participação das populações e num quadro de continuidade socioeconómica que resulte numa maior coesão interna no modelo de desenvolvimento dos distritos de Braga e de Viana do Castelo.

\section{Referências bibliográficas}

ALMEIDA, João F. de (2013), Desigualdades e Perspetivas dos Cidadãos: Portugal e a Europa, Lisboa, Editora Mundos Sociais.

AMARO, Roque, R. (1991), "Lógicas de espacialização da economia portuguesa", in Sociologia Problemas e Práticas, 10:161-182.

BADER, Veit e BENSCHOP, Albert (2018). "Desigualdade social: objeto e modelo proteórico de análise". In S. Gomes, V. Duarte, F. B. Ribeiro, L. Cunha, A. M. Brandão e A. Jorge (Orgs), Desigualdades sociais e políticas públicas, V. N. Famalicão, Húmus, pp27-29.

24 A desagrarização consiste no processo de decrescente dependência da população rural da atividade agrícola, enquanto a desindustrialização passa pela perda de participação do sector da indústria na produção total de um país ou região. 
BALTAZAR, Maria S. (2018). "Desigualdades territoriais em Portugal: da conceptualização às políticas públicas de desenvolvimento regional". In S. Gomes et al. (Orgs), Desigualdades sociais e politicas públicas, V.N. Famalicão, Húmus, pp.233-258.

BECK, Ulrich e BECK-GERNSHEIM, Elisabeth (2006), Individualization: institutionalized individualism and its social and political dimensions, London, Sage.

BENAVENTE, Ana et al (1996), A literacia em Portugal. Resultados de uma pesquisa extensiva e monográfica, Lisboa, Fim de Século.

CABRAL, Manuel V. (1979), Portugal na alvorada do século XX, Lisboa, Regra do Jogo.

CARDOSO, António (2012), Território e Desenvolvimento. Populações no concelho de Barcelos (1960-2011), Ribeirão, Húmus/CICS.

CARDOSO, Fernando Henrique e FALETTO, Enzo (1970), Dependência e Desenvolvimento na América Latina, Rio de Janeiro, Zahar Editores.

CARMO, Renato Miguel (org.) (2010), Desigualdades Sociais 2010. Estudos e Indicadores, Lisboa, Editora Mundos Sociais.

CARREIRA, Henrique (1996). "As políticas sociais em Portugal”. In A. Barreto (org), A situação social em Portugal: 1960-1995, pp. 365-477. Lisboa, ICS.

COSTA, António F. da (2012), Desigualdades Sociais Contemporâneas, Lisboa, Mundos Sociais.

CRISTÓVÃO, Artur et al. (1994). "Practises of endogenous development in Barroso, Northern Portugal" in J.D. van der Ploeg (org), Born from within: practise and perspectives of endogenous rural development, Assen, Van Gorcum.

DIOGO, Fernando; DIOGO, Ana M. (2013), Desigualdades no sistema educativo: percursos, transições e contextos, Lisboa, Mundos Sociais.

FERRÃO, João (1999), O desenvolvimento e as redes interterritoriais, Lisboa.

FERREIRA, Elisa (1993), Relatório sobre o Desenvolvimento do Vale do Ave, Porto, Comissão de Coordenação da Região Norte (policopiado).

FIGUEIREDO, Ernesto V. S. (1985), O Minho - Distritos de Braga e Viana: Alguns aspectos de definição espacial, população, estrutura agrária e produtos e culturas minhotas, Braga, Universidade do Minho.

FORTUNA, Carlos (1987), "Desenvolvimento e sociologia histórica: acerca da teoria do sistema mundial capitalista e da semiperiferia", in Sociologia. Problemas e Práticas, 3, 163-193.

FRANK, André Gunder (1961), Desenvolvimento e Subdesenvolvimento, Rio de Janeiro, Fundo de Cultura.

FRANK, André Gunder (1971[1966]), Sociología del desarrollo y sudesarrollo de Ia sociologia. EI desarrollo del sudesarrollo, Barcelona, Anagrama.

FURTADO, Celso (1961), Desenvolvimento e Subdesenvolvimento, Rio de Janeiro, Fundo de Cultura.

GIMÉNEZ, Ma del Mar. G. (1996), “La red social como elemento clave del desarrollo local: el caso de los programas Leader de Castilla y Leon", in Actas III Colóquio Hispano-Português de Estudos Rurais, Lisboa, Sociedade Portuguesa de Estudos Rurais.

GOMES, S., DUARTE, V., RIBEIRO, F. B., CUNHA, L., BRANDÃO, A. M. e A. JORGE (orgs) (2018), Desigualdades sociais e políticas públicas, V.N. Famalicão, Húmus.

GOMES, Maria do Carmo et al. (2000). "Novas análises dos níveis de literacia em Portugal: comparações diacrónicas e internacionais". IV Congresso Português de Sociologia, Coimbra, Associação Portuguesa de Sociologia.

GONÇALVES, Carlos (2007), "Dinâmicas do mercado de trabalho na região Norte". In C. Gonçalves (org), A região Norte de Portugal. Dinâmicas de mudança social e recentes processos de desenvolvimento, Porto, Instituto de Sociologia.

GONÇALVES, Carlos M.; PARENTE, Cristina; VELOSO, Luísa (2001), "Licenciados em sociologia: ritmos e formas de transição ao trabalho". In Sociologia, Revista da Faculdade de Letras, Vol. XI, pp. 31-94. 
GONÇALVES, Carlos, PARENTE, Cristina e VELOSO, Luísa (2004), “Licenciados em Sociologia e mercado de trabalho na transição do milénio". In Sociologia, Revista da Faculdade de Letras, vol XIV, pp. 253-297.

HOSELITZ, Bert F. (1982 [1953]). “Estrutura social e crescimento económico". in A. Figueiredo e C. Costa, Do subdesenvolvimento: 291-305, Porto: Afrontamento.

INE, Censos da População, 1981, 1991, 2001 e 2011.

INE, Anuários Estatísticos, 2010, 2011, 2012, 2017; Estatísticas Demográficas, várias.

INE, Estatísticas da Saúde de 2017 (edição de 2019).

INE, Inquérito aos Hospitais, 2013.

INE, Estudo sobre o Poder de Compra Concelhio 2015 (edição 2017).

KOVÁCS, Ilona (2002), As Metamorfoses do Emprego: Ilusões e Problemas da Sociedade da Informação, Oeiras, Celta Editora.

KOVÁCS, I. e Casaca, S. (2008), "Labour segmentation and employment diversity in ICT service sector in Portugal". In European Societies, 10 (3), 429-451.

LENINE, Vladimir (1971), Imperialismo, estádio supremo do capitalismo, Lisboa, Nosso Tempo.

LOPES, António Simões (1980), Desenvolvimento regional. Problema, Teoria, Modelos, vol I, Lisboa, Fundação Calouste Gulbenkian.

LUXEMBURG, Rosa (1967), La acumulación del capital, México: Grijaldo.

MAGALHÃES, Dulce (2007). "Escola e escolaridade no Norte de Portugal: práticas em mudança”. In C. Gonçalves (org), A região Norte de Portugal. Dinâmicas de mudança social e recentes processos de desenvolvimento, Porto, Instituto de Sociologia.

MARQUES, Ana P. (2005), "Educação e cidadania na Euro-região". In X. Bouzada (coord). Livro II, Politicas Sociais e Cidadania. Segundos Estudos Estratégicos do Eixo-Atlântico, INTERREG III A - Subprograma Norte de Portugal - Galiza. Fundo de Desenvolvimento Regional.

MARQUES, Ana P.; SILVA, Manuel C. e VEIGA, Carlos (2006), Assimetrias de Género e Classes. O caso das empresas em Barcelos, Barcelos, Kerigma e Universidade do Minho.

MENDES, Fernando R. (2005), Conspiração grisalha: segurança social, competitividade e gerações, Oeiras, Celta.

MONTEIRO, Alcides (2004), Associativismo e novos laços sociais, Coimbra, Quarteto.

MYRDAL, Gunnar (1970), The Challenge of World Poverty, Londres, Allen Lane.

MYRDAL, Gunnar (1974[1957), Teoria económica e regiões subdesenvolvidas, Rio de Janeiro, Edição Paz e Terra.

PARSONS, Talcott (1964), "Evolutionary Universals of Society”. in The American Sociological Review, 29, 339-357.

PÉREZ-YRUELA, Manuel et al. (1994), “Desarrollo local y desarrollo rural: consideraciones teoricas”, in Fórum, Sociedade Portuguesa de Estudos Rurais (SPER).

PINHEIRO, Luísa (2007), "As principais transformações ao nível das condições e da qualidade de vida na Região Norte". In C. Gonçalves (org), A região Norte de Portugal: dinâmicas de mudança social e recentes processos de desenvolvimento, Porto, Instituto de Sociologia.

PREBISCH, Raúl (1963), Dinâmica do desenvolvimento latino-americano, Rio de Janeiro, Editora Fundo de Cultura.

REIS, José (1992), Os espaços da indústria - a regulamentação económica e o desenvolvimento local em Portugal, Porto, Afrontamento

REIS, José (1994), "O desenvolvimento local é possível?" in M.B. Moreira (org), O desenvolvimento local é possivel?, Lisboa, Sociedade Portuguesa de Estudos Rurais, pp 3-16.

REMOALDO, Paula e NOGUEIRA, Helena (coord.) (2012), Desigualdades Socioterritoriais $e$ Comportamentos em Saúde, Lisboa, Edições Colibri.

RESENDE, José M. e VIEIRA, Maria M. (2003), “Educação". In Portugal Social, pp 69-89, Instituto Nacional de Estatística. 
RIBEIRO, Fernando B. (2018), "Afinal a riqueza não flui de cima para baixo: capitalismo, desigualdades sociais e ação do Estado". In Gomes, S. et al. (Orgs), Desigualdades sociais e políticas públicas, pp. 107-127. V. N. Famalicão, Húmus.

RIBEIRO, José A. C. (1984), Minho: Base Económica e Modelo de Desenvolvimento, Braga, Universidade do Minho.

RIBEIRO, José A. C.; CABRAL, Dolores e SOUSA, Ricardo (2000), Indicadores de desempenho económico - NUTS do Vale do Cávado: Análise Comparativa com as principais NUTS III do Continente, o Continente e a Galiza, Braga, Universidade do Minho, Escola de Economia e Gestão.

RODRIGUES, Carlos F., FIGUEIRAS, Rita \& JUNQUEIRA, Vitor (2012), Desigualdade económica em Portugal, Lisboa, FFMS.

ROSTOW, Walt W. (1960), Las etapas del crecimiento económico, Buenos Aires, Fondo de Cultura Económica.

SANTOS, Boaventura de Sousa (1985), "O Estado, as relações salariais e o bem-estar social na semiperiferia: o caso português". in Análise Social, vol XXI, 87-88-89, pp. 869-901.

SENNET, Richard (2001), A corrosão do carácter. As consequências pessoais do trabalho no novo capitalismo, Lisboa, Terramar.

SEERS, Dudley (1969), "The meaning of Development". in International Development Review, vol II, pp. 2-6.

SEN, Amartía K. (1999), Development as Freedom, Oxford, Oxford University Press.

SILVA, Manuel C. (1998), Resistir e adaptar-se. Constrangimentos e estratégias camponesas no Noroeste de Portugal, Porto, Edições Afrontamento.

SILVA, Manuel C. (2009), "Desigualdade e exclusão social: breve revisitação a uma síntese proteórica". Configurações, 5/6, 11-40.

SILVA, Manuel C. (2018). “Pobreza, Exclusão social e desigualdades: breve revisitação de conceitos e alguns dados a nível global e nacional". In Gomes, S. et al. (Orgs), Desigualdades sociais e políticas públicas, pp. 691:733, V. N. Famalicão, Húmus.

SILVA, Manuel C. e CARDOSO, António (2005), "O local face ao global: por uma revisitação crítica dos modelos de desenvolvimento", in M. C. Silva, A.P. Marques, R. Cabecinhas (orgs), Desenvolvimento e assimetrias socio-espaciais. Perspectivas teóricas e estudos de caso, Braga, Núcleo de Estudos em Sociologia e Inovação à Leitura.

SILVA, Manuel C. e CARDOSO, António (2003), "Assimetrias e dependências no desenvolvimento: a região do Minho no Noroeste peninsular". In Cadernos do Noroeste, série Sociologia, Vol. 21 (1-2): 189-216.

SILVA, Manuel C. e CARDOSO, António (2013). "Education, Culture and Social Exclusion: the case of Portugal". In Campion, M.; Moura, A.; Camargo, A.; Pabis, K.; Coquet, E.; Tipton, T. (eds), Changing The World: Social, Cultural and Political Pedagogies in Civic Education, pp. 17-29. Pedagogical University of Cracóvia, Universidade Estadual de Campinas, Brasil, Escola Superior de Educação/IPVC, Portugal, Universidade do Minho, Portugal, Krakow Editor, Polónia.

SILVA, Manuel C. e RIBEIRO, Fernando (2000), "Ciências Sociais e desenvolvimento regional e local no Minho". In Territórios Alternativos, Ciência e Desenvolvimento, 121-135, Lisboa/Grândola, ISCTE/ Câmara Municipal de Grândola.

SILVA, Manuel Carvalho da (2000), Acção sindical. Transformação e desenvolvimento, Porto, Campo de Letras.

SILVA, Susana (2007), "As recentes metamorfoses da saúde na Região Norte". In C. Gonçalves (org), A região Norte de Portugal: dinâmicas de mudança social e recentes processos de desenvolvimento, Porto: Instituto de Sociologia. 
STÖHR, Walter (1981), “Development from Below: The Bottom-up and Periphery-Inward Development Paradigm". in W. Stöhr e D. Taylor (orgs), Development from Above or Below?, Nova lorque, John Wiley \& Sons.

VILLASANTE, Tomás R. Prieto (1999), "Quatro redes para hacer transformaciones sustentables". in Política y Sociedad, 31:37-54, Faculdade de Ciências Políticas e Sociologia, Madrid, Universidade Complutense.

WALLERSTEIN, Immanuel (1990), "Culture as Ideological Battleground of the Modern World-System". in M. Featherstone (org), Global Culture, 31-56, Londres, Sage. 